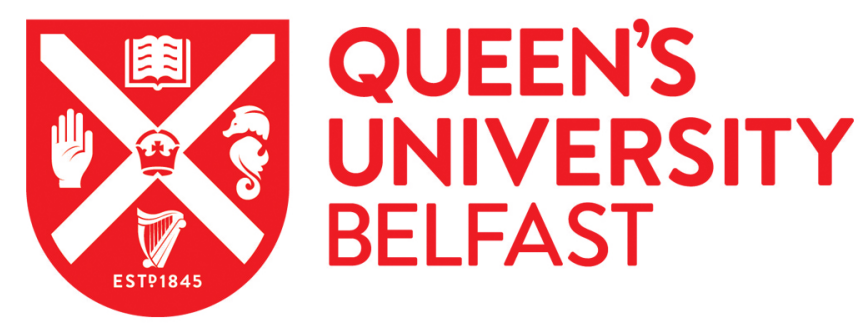

\title{
The Dynamics of Male and Female Street Prostitution in Manchester, England
}

Ellison, G., \& Weitzer, R. (2017). The Dynamics of Male and Female Street Prostitution in Manchester, England. Men and Masculinities, 20(2), 181-203. https://doi.org/10.1177/1097184X15625318

Published in:

Men and Masculinities

Document Version:

Peer reviewed version

Queen's University Belfast - Research Portal:

Link to publication record in Queen's University Belfast Research Portal

Publisher rights

(C) 2016 The Authors.

\section{General rights}

Copyright for the publications made accessible via the Queen's University Belfast Research Portal is retained by the author(s) and / or other copyright owners and it is a condition of accessing these publications that users recognise and abide by the legal requirements associated with these rights.

Take down policy

The Research Portal is Queen's institutional repository that provides access to Queen's research output. Every effort has been made to ensure that content in the Research Portal does not infringe any person's rights, or applicable UK laws. If you discover content in the Research Portal that you believe breaches copyright or violates any law, please contact openaccess@qub.ac.uk. 


\title{
Forthcoming: Journal of Men and Masculinities
}

\section{DOI: DOI: 10.1177/1097184X15625318}

The Dynamics of Male and Female Street Prostitution in Manchester, England

\section{Graham Ellison $^{1}$ and Ronald Weitzer ${ }^{2}$}

\begin{abstract}
This paper examines male street prostitution in Manchester, England, and draws some comparisons to its female counterpart in this city. While the two sectors have some important similarities, we also find significant differences in the physical and social ecology of the places in which they work, in their behavior patterns, and in individuals' demographics and work experiences. We find that ecological differences between the male and female markets have a major impact on participants' work practices, opportunities, and integration into the local community. The data also indicate that it is incorrect to speak of a monolithic male street market or sector in Manchester because sellers shift between settings (street, bar, escorting), unlike the female street sector. We also find that the males demonstrate more diversity in their repertoires for earning money. The findings have implications for local government policy and for outreach workers who work with these populations.
\end{abstract}

Keywords: sex work, prostitution, sexuality, social ecology, urban economy

\footnotetext{
${ }^{1}$ Queen's University, Belfast, Northern Ireland

${ }^{2}$ George Washington University, Washington DC

\section{Corresponding Author:}

Graham Ellison: Institute of Criminology and Criminal Justice, School of Law, Queen's University, Belfast BT7 1NN, Northern Ireland.

Email: g.ellison@qub.ac.uk
} 


\section{Introduction}

The vast majority of research on prostitution focuses on female sex workers (Dennis 2008), but research on males has grown over the past decade. Studies of male sex workers (MSWs) document both similarities and differences between them and their female counterparts. Both are stratified by type: street, bar, brothel, escorting. Like females, males on the street often have a history of parental abuse, foster care, or homelessness; are runaways from home; use drugs; commit petty crime; and may engage in "survival sex" due to a lack of other income options (Calhoun and Weaver 1996; Davies and Feldman 1999; El-Bassel 2000; Lankenau 2005; Leary and Minichiello 2007; McCabe 2011; Morse et al. 1999). For individual men and women, the specific pathways into street prostitution vary but tend to be characterized by less agency than for those who enter the trade by working in brothels or bars or as escorts (Koken et al. 2010; Weitzer 2009; West 1993). Street-based MSWs confront some of the same risks as their female counterparts, but some studies have found that MSWs are less vulnerable to victimization from others and appear to have lower commitment to health-related harmreduction techniques (Aggleton 1999; Calhoun and Weaver 1996; Lankenau 2005; McKeganey et al. 1990; Minichiello et al. 2013; Porter and Bonilla 2010). And, like female workers in the middle- and upper-tiers, similarly situated males are more likely than street workers to hold positive self-images and views of their work (Minichiello 2001; West 1993). Economic motives are central for both male and female sex workers, but many males are also motivated by the potential for sexual adventure and pleasure, whereas sexual satisfaction is less salient for many female providers (van der Poel 1992; Weinberg et al. 1999). Compared to women, males also tend to be involved in commercial sex more sporadically, drifting in and out of prostitution and leaving the trade earlier; in greater control over their working conditions; less likely to have exploitative managers; and more diverse in their sexual orientation (Aggleton 1999; Weinberg et al. 1999; West 1993). 
This paper builds on previous studies of male street prostitution. While it is well established that male sex workers vary demographically and experientially by sector - street, bar, escort, sauna - scholars have been less attuned to the ways that some street-based workers routinely move between the sectors. In Manchester, male sellers often work across multiple arenas as the need and opportunity arises. This variegation challenges traditional understandings of male street-based sex work, which tend to portray it monolithically.

Manchester is unusual in the UK in having a dedicated Prostitution Forum (staffed by city council officials, health and social care professionals, police, and outreach NGOs). The Forum adopts a harm-reduction rather than a law enforcement stance to prostitution, and also publishes an inter-agency strategy document: The Manchester Prostitution Strategy (Manchester City Council 2014). This document describes female and male street prostitution as analogous in many respects and does not take into account the complexities and variations within the male street population. Our paper examines these and other features of male street work in comparison to the city's female street market.

Such comparison is important for the crucial task of identifying aspects of sex work that are highly gendered versus those that are generic (Dennis 2008; Weitzer 2009). Previous studies (some cited above) have gone some way toward disentangling the gender-neutral and gender-specific dimensions of sex work, but few of those studies compare men and women working in the same echelon in the same city - the superior research design for identifying similarities and differences by gender (Koken et al. 2010; McKeganey et al. 1990; Weinberg et al. 1999). For both of our street sectors, data were collected on participants' demographics, sexual orientation, substance abuse, victimization, income-generating practices, and use of public space.

In addition to the paper's comparative gender framework, it is situated theoretically within the literature on the social ecology of red-light districts. This literature has a long lineage, 
dating back to the Chicago School of sociology in the 1920s and 1930s. The Chicago School examined (1) the ways in which deviant behavior can be shaped by the social and physical conditions of distinct areas of the city (Shaw and McKay 1942) and (2) the reasons why social problems (poverty, crime, social disorganization, etc.) and vice (drugs, gambling rackets, prostitution) cluster in certain locations. Walter Reckless concluded that, "Vice resorts concentrated in those tracts of the city which showed the highest rate of community disorganization," measured by rates of crime, venereal disease, divorce, and poverty (Reckless 1933, 252), and he argued that "decaying neighborhoods have very little resistance to the invasions of vice" because of the marginality of the inhabitants (Reckless 1926, 165). The Chicago School presented a fairly uniform picture of red-light districts: In places of such "vast social disorganization, personal taboos disintegrate and appetites become released from their sanctioned moorings," resulting in rampant deviant behavior (Reckless 1926, 168). Similar characterizations of vice areas - anomic, disorderly, criminogenic - continue to be made today and have served as grounds for zoning ordinances that restrict or ban sexually oriented businesses from areas of the city.

Scholars have recently begun to challenge this monolithic depiction of red-light districts (consisting of either street prostitution or indoor erotic businesses) and the claim that they are necessarily located in disorganized and "decaying" communities. In fact, there can be important differences among such zones even within the same city. Some red-light zones fit the disorganization model well, while others can be found in stable, middle-class, low-crime areas of the city (Ashworth et al. 1988; Linz 2004; Prior and Crofts 2012; Weitzer 2014; Weitzer and Boels 2015). Some are single-use erotic spaces, largely confined to a particular type of activity, while others are multi-use. Single-use zones typically have "few or no spatial links with a wider entertainment industry" and may have few amenities for those who work there (Ashworth et al. 1988, 208). Prostitution in mixed-use areas may take a rather different 
form because of the wider array of amenities and the potential integration of sexual commerce into the surrounding social and economic order. For both sellers and customers in multi-use areas, "advantages are maximized by the location of prostitution close to other entertainment facilities" (Ashworth et al.1988, 208). And the visitor gets "the opportunity to view other goods and services they may not have previously been aware that they wanted" (Cameron 2004, 1653).

We apply this ecological perspective to our examination of the physical and social features of street prostitution in Manchester, finding that one of the red-light zones is consistent with the single-use model, while the other operates in a mixed-use context and allows for more integration of sex workers into the socio-economic life of the community. Of particular interest are the implications of the two community's physical and social ecology for the behavioral practices and options available to the sex workers who operate there.

\section{Research Methods}

The findings presented here are based on ethnographic research conducted in Manchester, England, during 2013-2014, which was approved by the authors' university ethics committees. ${ }^{1}$ Manchester was selected as the study site because it has one of England's largest gay communities and commercial districts as well as a long reputation as a place where young men sell sex to other men in the central gay district (known as "the Village"). Manchester also has an established female street prostitution zone.

Field research took place in 2013 and 2014. We first identified areas of the city where street prostitution occurs and conducted 130 hours of observations in these places.

Observations consisted of documenting their spatial configuration, diagramming their composition (e.g., amenities, businesses, residences), noting the physical condition of the area, and observing individual behavior and interactions. Observational data were recorded in 
handwritten field notes. While structured, formal interviews were not conducted with sex workers, in the course of our observations we were able to engage in loosely structured conversations with 15 male sex workers who were met in solicitation areas and in bars and clubs in the Village. Key aspects of these conversations were recorded in handwritten field notes. Information on female workers was obtained via our ethnographic observations, our interviews with stakeholders who have expertise regarding this sector, and from some prior studies (Hester and Westmarland 2004; Pitcher et al. 2006).

For the stakeholders we interviewed, our questions were initially derived from a review of the Manchester Prostitution Strategy document (mentioned above) and from our field observations in the two solicitation areas. Other interview questions emerged organically in the course of interviewing. Interviews were digitally recorded with the respondent's permission, and an informed consent form was provided to each respondent. Interview questions for service-providing NGOs inquired about both the work the organization does and detailed information regarding the population it serves. ${ }^{2} \mathrm{We}$ triangulated the interview data with street-level observations in order to cross-verify data between the various sources. Data analysis was organized around the "constant comparison" method that is common in qualitative studies: identifying similarities and differences between the male and female sectors as well as any significant variations within each sector.

We conducted formal interviews with organizations that conduct outreach work with male and female street sellers. The perspectives of these organizations are important because they are in a good position to provide an assessment of what is happening on the ground and are attuned to changes in the dynamics of commercial sex in Manchester over the years. Collectively, they have nearly 70 years of experience working with male and female sex workers: 
- The Men's Room started off as an arts-based skills project for MSWs, but has expanded into providing social and health services. This organization operates a weekly drop-in center where MSWs can socialize;

- Manchester Action on Street Health (MASH) provides sexual health screening and other services to female sex workers;

- National Ugly Mugs provides assistance to male and female sex workers who experience violence and abuse;

- Lifeshare was traditionally involved in providing services to homeless young men who sell sex, but now provides assistance to all MSWs.

None of these organizations has religious or political affiliations and each takes a strictly nonjudgmental stance regarding prostitution. We identify the four organizations by name here, but use pseudonyms for all sex workers in order to maintain their anonymity.

\section{Findings}

\section{Physical and Social Ecology}

The male street market is dispersed around the gay Village, extending to an area known as "the bridge" over half a mile away along a section of the canal towpath. The Village is now a pedestrian zone hosting over 50 gay bars, restaurants, clubs, saunas, sex shops, hotels, and convenience stores (see Figure 1). Historically, this area provided many hidden places for public sex to take place, whether paid or unpaid, and both male and female sex workers "were able to ply their trade from licensed premises, street corners, and along the canal towpaths" (Whowell 2010, 131). But the area has become increasingly commercialized and gentrified in line with the city council's planning policy, and it has been characterized as a "utopian hedonistic gay male space, absent from violence, tolerant, and cosmopolitan" (Binnie and Skeggs 2004, 49). 
Complaints from local residents and merchants were important in prompting efforts to shift female street prostitution away from the Village:

Traditionally, the women worked near the gay Village, but once the area started to be redeveloped - with all the fancy bars and so forth - we [the council] started to get lot of complaints from businesses and from people who were being hassled when they were going to the pubs. That's when we decided we really needed to develop a strategy to deal with street prostitution. (City Council official)

This urban redevelopment resulted in the forced displacement of female street sellers to their current location (Atkins and Laing, 2012). Recently, however, it is male street prostitution in the Village area that is viewed as a nuisance - catalyzing increased police enforcement. Yet this has only served to disperse male sellers across a wider geographical area (discussed below).

$<<$ Figure 1 here - photo: the Village $>>$

Female street prostitution is spatially compressed in Manchester, now located in an industrial park near the main train station in a mainly non-residential area. It is surrounded by the legacy of Manchester's past industrial heritage: warehouses, factories, and some businesses. The area is poorly lit, run-down, lacking in amenities, and sparsely populated after the nearby businesses close in the evening (see Figure 2). Litter, used condoms, and other detritus dot the streets. The lack of residences in the area means that complaints to the authorities from the public have been rare. And while the police do not call this a 'tolerance zone' per se, street prostitution is informally tolerated. As our police respondent remarked, I wouldn't use the term "tolerance zone," since that implies that you have certain provisions in place for safety. But I suppose our point would be that if the women keep to a particular area, are fairly low-key, and don't generate complaints from the public, then enforcement is unlikely. (Interview, Greater Manchester Police official with a responsibility for prostitution). 
$<<$ Figure 2 here - female street zone $>>$

A key difference in the way that male and female street commerce is transacted in Manchester concerns the use of space, i.e., how the landscape is utilized and how this use evolves over time. Like other UK cities, female sexual commerce follows the traditional pattern of women standing around soliciting and waiting to be picked up by drivers. Some of the women occasionally move to different parts of the main stroll or some adjacent sidestreets, but generally they stick to the confines of their chosen turf.

Solicitation methods differ radically between the two markets. The dynamic in the female beat is shaped by its single-use character and its isolation from both the city center and from neighborhoods that feature a lively night-time economy. Sexual encounters in the female beat are interactionally limited. In the male sector, clients often leave their cars and mingle with the MSWs on the bridge, stroll along the canal towpath, or take a MSW for a drink in a nearby bar. As one respondent stated:

Some clients are quite brazen and will hang out with the lads, or walk up to a lad and say "have you seen a [specific] lad about; do you know where he is?" You wouldn't find that in the female sector at all. In the female sector you would only approach someone if you wanted to do business with them. (Men's Room interview)

Unlike the women, MSWs were observed to be quite spatially mobile: few of them would spend any longer than 30 minutes in any one place before moving on to another solicitation area. The practice of frequent walking thus becomes a component in MSWs' creation of their "beat space" and a way to negotiate sexual encounters with clients (Atkins and Laing 2012, 622). Some MSWs were observed constantly making a loop between the bridge at the far end of the canal to the Village and back again (a round-trip distance of one mile) in search of prospective clients. The bridge (in Figure 3) is an established epicenter for 
male sexual commerce: it allows easy access to vehicular traffic, provides sufficient lighting to see what is happening, and offers enough anonymity for drivers to park without attracting attention.

$$
<<\text { Insert Figure } 3 \text { here }- \text { photo of the bridge }>>
$$

MSWs cruise the bridge or the towpaths below it either individually or in small groups. Other MSWs were observed sitting in small groups at outside tables in the Village or in a nearby park where they hope to meet a prospective client leaving one of the area's bars. In some cases, one's "beat space" is determined by the perception of clients who frequent particular spots. One MSW, for example, stated that he "never goes near the bridge because you only get pervs and weirdos there." Generally though, spatial mobility occurs to a far greater extent among the males than their female counterparts.

Mobility can occur across types of sex work as well. In terms of cross-sectoral mobility for female sellers, our informants were emphatic that there was negligible movement between the street sector and indoor venues (MASH interview; National Ugly Mugs interview). These respondents noted that indoor establishments (e.g. massage parlors) had strict policies on drugs and alcohol and that the often chaotic lifestyles and substance abuse habits of female street workers would largely preclude them from working in indoor settings and particularly those with rules imposed by management (cf. Weitzer 2012). By contrast, a number of MSWs that we either spoke to or observed in action appeared to switch between the sectors with relative ease. For some, it does not appear that there is a preference for one sector over another. Rather they select options for what is most appropriate at a particular time depending on the circumstances, with some alternating between the street, a bar, a sauna club, or escorting. This fluidity can be illustrated by a MSW who we met near the bridge. Adam (age 20) stated that he was gay, a student, had no drug problem, and came from a stable family. He 
normally worked from the Internet and produced his mobile phone to show his profile on one of Manchester's male escort websites. But he sometimes picked up clients on the bridge or towpath "if things are slow on the net" - the problem being that he had to reduce his fee when working on the street (his usual $£ 100$ charge being reduced to $£ 50$ for street work). This fluidity between the street and escort sector was described as follows:

Now, even the more chaotic street lads who never went on the Internet before are starting to use Grindr, Craigslist, Gay Swap, and the free advertising websites. And we have seen a huge increase in the number of lads who have the Internet on their phone. They are not paying to advertise profiles on the escort websites; they are able to advertise on the free ones. So we are seeing a far more fluid situation between the street and the Internet than a couple of years ago. (Men's Room interview)

Other MSWs rotated between the street and bar work. One bar near the Village has a longstanding reputation for facilitating commercial contacts between young MSWs and old male clients (National Ugly Mugs interview). The bar does not enforce a dress code, has no security at the door, and does not seem to mind MSWs being on the premises so long as they do not cause trouble and are on good terms with the manager (Atkins 2013). One MSW explained, "I would come here at least two or three times a week, and I will usually meet someone.... I'd maybe do the canal too the odd time, but it's warmer in here plus there's always somebody to chat to." We observed spatial mobility both within the indoor sector (men visiting multiple bars in search of clients) and between the bars and the streets.

\section{Sex Worker Characteristics}

Based on both our interviews and observations, it is clear that the demographic profile of Manchester's male and female street prostitutes differs considerably. From a total of 150 female street sellers known to service providers, most of them are white and British, from the Manchester area, and significantly older than the MSWs. The average age of female street 
sellers is early to mid-30s, with a few in their 50s and 60s; it does not appear that underage girls work on the street (MASH interview; police interview).

Although most of the women are British, over the past few years there has been an influx of Romanians. Currently, an estimated 10-15 percent of street sellers are Romanian (MASH interview). MASH engages in substantial outreach work with female sellers, but “what we don't know about, and really don't understand at the moment, are the Romanian women" (MASH interview).

The Romanians are younger (18-25) than the British women. By soliciting on the same street as their British counterparts, the two groups have become embroiled in something of a turf war (National Ugly Mugs interview). Conflict revolves around a number of issues: Romanians' cheaper prices; working in a space that British workers had traditionally claimed as theirs; their aggressive solicitation tactics (i.e., walking in the street, flagging down cars, approaching clients directly); and the fact that "they will dress in a more risqué way than girls have historically done in Manchester, which means wearing virtually next to nothing" (police interview). Local sellers believe that the growing complaints from nearby businesses and heightened levels of police enforcement actions are due to those Romanians who were not abiding by the established norms. In addition, there is a perception that the Romanians undercut their British counterparts by engaging in unsafe sexual practices. (Our MASH respondent stated that some of the Romanian sellers had a very limited knowledge of sexualhealth precautions.) We would point out that it is fairly common for Western European sex workers to draw invidious distinctions between themselves and new arrivals from Eastern Europe: disparaging migrant sex workers for the very reasons described above (Marttila 2008; Tani 2002; Weitzer and Boels 2015).

Lifeshare estimates that there are between 60-100 male street sellers in Manchester. Compared to female sellers, the males are considerably younger. The overwhelming majority 
of MSWs are aged between 16 and 20, although younger boys have recently been involved as well (Lifeshare interview; Men's Room interview). It is these youths who social services, the police, and the various outreach NGOs attempt to identify early on, given their concerns about the sexual exploitation of minors. Respondents suggested that the males' ethnic and nationality background was invariably white British, with the vast majority identifying as heterosexual. Very few Black and Asian men sell sex on the street in this city, preferring to use the Internet instead (Men's Room interview). Most street-based MSWs come from the Greater Manchester area, though there are also some from other cities and towns:

People sometimes come into the city for the reason of selling sex in the Village.... But you have people who end up in Manchester for all different reasons. Some might come because they hear that it is easy to make money from selling sex in the Village; others come to Manchester and then fall into sex work even though it wasn't something they had planned to do initially. (Lifeshare interview)

Regarding age, youth and vitality are privileged within mainstream gay culture (Johnson 2008), so there is much less of a market for older MSWs than there might be for their female equivalents. One of our respondents noted that not only did the MSW have to be young but also had to dress in a particular way: "It is that young boy look, your typical 'scally lad' wearing a tracksuit, hoodie, and Nike or Adidas trainers. Someone who looks like a really straight male, or a gang member [aged] about 16-20" (Lifeshare interview).

The appeal of young MSWs and their "scally lad" look resonates broadly in gay popular culture, but it is also particularly alluring on the male sex work scene. The image of the scally or chav is "increasingly commoditized across the sex industry. Internet escorts will pose in tracksuits . . . to solicit custom, and 'chav' identities can be readily found in pornography" (Whowell 2010, 137). In the UK the terms "scally" and "chav" are somewhat pejorative terms directed at young working-class males. However, the attraction of "rough" working-class males to a middle- or upper-class clientele has a history dating back to the late 
Victorian and Edwardian period, when "rough" became eroticized in gay circles and "rough trade" became associated with working-class male prostitution (Brewis and Jack 2010). While many young British working-class males dress in tracksuits, hooded tops, and trainers, a "scally" or "chav" identity also forms a core component of the MSWs "sexual choreographies" insofar as it is something actively cultivated to solicit business (Atkins and Laing 2012; Whowell 2010). This attire is also important because it allows MSWs to blend inconspicuously into Village life and the lively night-time scene. And this is yet another key difference between the male and female sectors:

The females are much more noticeable ... it's not exactly a uniform, but you can usually tell by the boots, the short skirt, the makeup, or if they look a bit racy. . . W With the men you could walk around the Village and you would find it very difficult to identify a male sex worker or even know what to look for. ... With all the men in the Village, the sex workers tend to blend in. (Lifeshare interview)

Our respondents stated that the working life of a male street worker is quite short, and considerably shorter than for their female counterparts (cf. Weinberg et al., 1999). Most male street sellers would experience considerable difficulty attracting clients by the time they reached their mid-20s:

Male sex workers have a very short shelf life. Your shelf life might be until you are 23 or 24, but you can't work the street if you are too old. For those men who maybe have a baby face, they can get away with working maybe a couple more years but not really much beyond that. You simply wouldn't be making any money. (Lifeshare interview)

The options for MSWs who have approached the end of their working life are limited. Some, providing they have access to their own place and the Internet can move online, others may pick up a regular clientele or are befriended by older men, but often this means the provision of food and accommodation in return for sex rather than cash (Lifeshare interview, Men's Room interview); while others will resort to desperate and drastic measures: 
They end up doing a desperation crime that lands them a custodial sentence. Over the years I have seen somebody struggling to get punters [clients] and he has then done something like a street robbery out of desperation, where before he wouldn't have dreamed of doing something like that. (Men's Room interview)

\section{Gender and Sexual Identity}

Research indicates that MSWs identify variably as homosexual, bisexual, or heterosexual and service a male clientele that is equally varied in terms of its sexual orientation (Aggleton 1999; West 1993). In Manchester, sexual orientation marks an important difference between male and female sectors. Men who sell sex to other men are more likely to identify as heterosexual than female sellers are to identify as lesbian, as our respondent from MASH explains:

I would say that nearly all the working women on the street identify as heterosexual.... They all have male partners or boyfriends. I am not aware of any lesbian [street working] women who sell to heterosexual punters. I have never even heard of it happening. (MASH interview).

Both MSWs and their clients are diverse in terms of their sexual orientation. A majority of MSWs in the Village identify as heterosexual and may have girlfriends, but nevertheless engage in paid sexual encounters with men, chiefly for reasons of economic necessity (Atkins, 2015). Mark had his first sexual encounter with another man in prison: "I kind of liked it, just being with another lad. ... I wouldn't come down here [to the Village] that often, but I would when the girlfriend's away." Gavin, who also identified as "straight," had recently been released from his job as a mechanic: "So that's how I ended up down here [the Village]. It's not too bad; I've met some good mates." Others indicated that they were gay or bisexual. Daniel, for example, is bisexual and sells the party drug Ketamine in the Village along with his girlfriend, but when she isn't there he would sometimes sell sex. For the bi and gay sub-sectors, there is considerable fluidity between paid sex and casual sex - i.e., getting 
paid for an activity that one enjoys anyway and with the commercial aspect also having a social dimension, such as going to bars/clubs with clients.

At one pole, therefore, are the heterosexual men, a majority of whom engaged in the "survival sex" mentioned earlier in the paper. At the other pole are young men who identify as gay or bisexual and see commercial sex more opportunistically and as an extension of their gay or bisexual identity. As one of our Men's Room respondents suggests:

There is a spectrum within the male sex work scene, from the lads who self-identify as straight and who are just doing it as a way of getting a bit of extra money to the lad who identifies as gay and this is just one part of their identity. So the gay lad wouldn't necessarily see the selling as problematic. He is having sex and getting paid for it, so he'd be thinking "what's the problem"? . . . We also see gay lads who would say, "If I fancy him, I won't charge him". . . . So not all their encounters would necessarily involve money changing hands if they happened to like the client. You would never get that in the female street sector: It would be very, very rare to give freebies.

Thus, commercial sexual transactions are not always strictly "commercial” but may also involve intangible sexual or social benefits for the seller. For some gay or bisexual males there is often a blurring between what they see as commercial sex and casual sex. Furthermore, our respondents suggested that a person's sexual orientation could have some impact on a MSW's life chances and whether he would be involved in crime, have altercations with the police, and be in a position to leave prostitution to find alternative employment. As one of our respondents remarked:

Young straight men for whatever reason - a lack of educational qualifications or whatever - simply don't have the same access to routes out of sex work as some young gay men. There is always something in their background that is holding them back. And we would see far lower levels of criminality or involvement with the criminal justice system among the gay lads. Even if a young gay man was kicked out of home by his parents, chances are he still went to school and got his qualifications [diploma]. That means there is something the lad can do with his future. Many of these gay lads 
would be in a job by their mid-20s or early 30 s.... That is much less likely to happen for the straight lads. (Men's Room interview)

\section{Drug and Alcohol Abuse}

Research on other cities finds that substance abuse is often a feature of female street prostitution (e.g., Balfour and Allen 2014; Porter and Bonilla 2010; Scott 2001). Abuse of alcohol, heroin, and crack cocaine is prevalent among the British female sellers in Manchester, and often a pathway into selling sex to support the habit. As one of our respondents put it, "Class A [hard] drug abuse is a huge problem for the female sellers absolutely. The majority have got problematic drug and alcohol use and mental health problems" (MASH interview).

Some studies find hard-drug use among street-based MSWs (McCabe 2011; Minichiello et al. 2013; National Advisory Committee on Drugs 2009), but other studies find lower rates of hard-drug use among males than their female counterparts (e.g., McKeganey et al. 1990; Weinberg et al. 1999). In Manchester, hard drug use was not reported by our respondents nor evidenced in our observations of MSWs. As one or our interviewees remarked,

It is something that never ceases to amaze me. There is quite a high use of heroin and crack cocaine on the female beat, but on the male beat there is not much Class A [hard] substance abuse. Sometimes on the male beat it can be alcohol and cannabis, but heroin is not up there at all. Most of the lads we see wouldn't be heroin users. (Lifeshare Interview)

\section{Another respondent concurred:}

It's presumed that a lot of the lads are heroin-injecting users, but we don't see that. It's much more experimental: cannabis use across the board and what you might call "party drugs"... . Sometimes the drugs happen because of the sex work and they might take a 
bit of coke with a client; but [cocaine] wouldn't be something they would do on their own at all. (Men's Room interview)

The use of alcohol and cannabis can be a way of mitigating the shame that some young men feel by having to sell sex, or a way of relieving the relative tedium of hanging around the Village to find clients, or a way of psychologically managing other problems (Men's Room interview). But it remains an open question whether their consumption of alcohol and cannabis is largely a function of their sex work or whether it needs to be seen in the context of the social life of many young Britons more broadly. The Institute for Alcohol Studies (2013) reports that British youth have one of the highest levels of binge drinking in Europe.

\section{Risk and Danger}

The literature indicates that street sex work is typically more dangerous than that which takes place indoors (Scott 2001; Weitzer 2012). Our research indicates that one of the few areas of commonality between Manchester's male and female sectors concerns the risks they face on the streets. The risks are considerably higher on the street than in bars, clubs, or massage parlors.

Nevertheless, there are some differences between the male and female sectors in relation to these hazards. For female sellers, the risks come from micro-aggression on the part of bystanders: men and women who drive by and engage in spitting, name-calling, or throwing objects at them. Women also face the threat of serious physical or sexual violence from clients or other men on the street. Our respondents from MASH and the police recounted several incidents where female street workers had been subjected to serious assaults. In March 2013, for example, a man visited the MASH office where he made derogatory comments about "prostitutes" and later that day sexually assaulted four sex workers (Slater 2013). According to our MASH informant, this incident was a "wake-up call" for the police 
and led to discussions between the police, MASH, and sex workers about improving safety in the area. As a consequence, the police increased their patrols for harm reduction (not enforcement) and told sex workers that they would take action against perpetrators if incidents are reported to them (MASH interview).

Violence from clients is a risk for MSWs as well, but this risk is mitigated to some extent by the youth and physical strength of many of the MSWs. The victimization of male sex workers is also connected to the complex ways in which young men "do gender," with many of them feeling that they have to act out traditional masculine roles (West and Zimmerman, 1987). For example, many male MSWs rationalize or deny victimization out of a concern of being perceived as feminine or weak. As Mark (19) suggested "I've been chased by gangs of lads down on the towpath before, but it doesn't bother me. . . I'd lash out myself if I had to." Furthermore some MSWs are fatalistic and view physical risks as "part of the job, not something they can get help or support with. It's just an occupational hazard for them" (Men's Room interview). In other instances, young MSWs sometimes experience violence from each other during disputes over alcohol, drugs, money, girlfriends, or clients (Aggleton 1999; Leary and Minichiello 2007; West 1993). But what appears to be more common is victimization by groups of young men who come into the Village to rob and attack others whether sex workers or those cruising for unpaid sex - along the secluded stretch of the canal towpath. Assaults on men in this area are commonplace, although significantly underreported (police interview; National Ugly Mugs interview).

\section{Repertoires}

The notion of behavioral "repertoires" is relevant to the current study. Repertoires of behavior refer to the various subcultural "tool kits" or strategies that individuals can creatively draw upon in responding to particular situations in their lives (Staats 1995; Swidler 
1986). One NGO respondent from The Men's Room used the very term "repertoires" to explain the various strategies that MSWs employ to generate income, which ranged from selling sex to various scams to criminal conduct. For the majority of MSWs, their spatial mobility - the constant walking the canal beat in search of clients - provided many opportunities for engaging in such enterprising practices, unlike the female sex workers.

Selling sex was rarely the sole income-generating method among MSWs, but rather was one on a continuum of enterprising ways of earning money (cf. Leary and Minichiello 2007; Weinberg et al. 1999). Our Men's Room interviewee explained that when MSWs cannot find clients some will improvise and resort to a crime such as a street robbery, which often will result in a custodial sentence. At the lower end of the spectrum, shoplifting was fairly common amongst MSWs, judging by the numbers referred to NGOs from the Probation Service (Men's Room interview). In fact, it appears that a certain amount of low-level crime is part of the tapestry of male street prostitution in Manchester. Location contributes to this dynamic, insofar as the Village's lively night-time economy provides opportunities for economic crime. Given their spatially isolated location, female sellers are much less likely to be involved in robberies and thefts (MASH interview).

Other tool-kit repertoires involve scams. The practice of "clipping" is one such scam whereby MSWs collaborate to scam a client out of money but without providing any sexual service. Clipping involves one MSW pretending to be underage with another threatening to report the client to the police. Ryan and James are MSWs and while Ryan is 19 he looks considerably younger. James describes how the practice works, though in this case revenge was also a key motivation:

There's a bloke always hanging round the bridge, and I went with him one night but the fucker only gave me $£ 20$ when he said he would give me $£ 40$. So I see him another night and I says to Ryan "jump into his car and I'll run up to it" and then say "that lad is 
underage, I'm going to the coppers [police]". ... We ended up making the cunt drive to a cash machine and got $£ 200$ off him.

Other scams include selling drugs or fake or stolen goods. These schemes can backfire and the "lad can end up getting a kicking from doing that, particularly if they mess with the wrong people" (Men's Room interview). However, the sale of recreational drugs around the Village - an area noted for both drug dealing and consumption - is a key way in which a MSW can supplement his income: "It is often the lads making the most money who are the ones selling drugs as well ... weed mainly; we are not talking about heroin or coke. They will be selling drugs to other lads and the people visiting the Village. That's quite common" (Men's Room interview).

The overlap between selling sex and drugs can be illustrated by considering the case of Daniel. The researchers met Daniel (age 21) in a park near the Village where he was chatting and joking with some friends. He stated that he sold sex around the Village but he never went near the bridge, and wouldn't necessarily go with any client: "I would have to like the look of them, I'm very fussy." In many ways Daniel did not fit the stereotypical profile of the male street prostitute. He was articulate, came from a stable family, and his parents were middle-class professionals residing in a residential suburb. While his early school career was checkered because of truancy and other behavioral problems, he nevertheless graduated from secondary school and was currently studying at a local college. However, Daniel had frequent run-ins with the police for dealing recreational drugs and eventually served a short custodial sentence. But as he explained, there was a lucrative market for the sale of Ketamine which he continued to sell around the Village often in partnership with his girlfriend. 


\section{Belonging, Camaraderie, and Status}

According to our respondents, the culture of the Village and the sociability it offers made it difficult for MSWs to consider leaving sex work. In several cases, young men had exited and found other employment but later returned to the Village. Unlike their female counterparts, the reasons for this return had as much to do with finding a sense of purpose as making money: "they have a role in the Village that, in an odd way, makes them feel wanted" (Men's Room interview). The Village provides a sense of belonging in a context where the men, like many other British youth, feel marginalized by society (Young 1999). As a respondent noted, "Many of these young men feel that they have been left behind by society, which in a sense they have" (Men's Room interview), and it is primarily through selling sex in the Village that they develop a sense of purpose and belonging. The latter includes camaraderie with other sex workers and the potential for enhanced self-worth as a result of their interactions with clients. A study of male migrant sex workers in Europe reported that these youths prefer sexual commerce to other jobs because the former offers a type of "social interaction where they are valued and desired" (Mai 2011, 1244).

The sense of purpose that the Village provides is reflected in a degree of camaraderie and belonging among MSWs that does not appear to exist in the same form for female sellers. For the males, both commercial sex and its associated enterprises (scams, petty crime) reflect an intersection of male sex work with the Village street culture:

What the lads do is very much connected to the city-center street culture which the lads would also be part of. ... Some of that might be involvement in criminality, drugs, drinking, hanging around in bars or video arcades, playing the slot machines, or just sitting about. To see [male] sex work in isolation [from street culture] misses the whole sociability thing in a way that isn't quite the same on the female beat. (Men's Room interview) 
Unlike the women, many of the young men frequently walk the beat together while cruising for clients and spend long periods of time socialising in each other's company. While female sellers may chat briefly with each other on the street, they do not engage in extended periods of interaction and generally work in isolation. But while the camaraderie of the male street scene can be a powerful attraction, positive outcomes should not be overstated. Young men also compete with each other for clients and some of them exploit or abuse other MSWs. In addition, we discovered a status hierarchy that is more developed among the men than their female counterparts: "There is definitely a pecking order among the women. A more established worker will very often get a prime spot on the street" (MASH interview). But this status hierarchy does not extend beyond the confines of the job into one's personal life, whereas for young males the hierarchy is both more extensive and open to continued renegotiation. Observing the interactions between MSWs in the Village, the nearby park, and the bridge, it was clear that some had attained higher status than others. In some interactions, certain young men who seemed to have a particular status within the group were observed ordering other MSWs to go and get them food, alcohol, or cigarettes from a nearby convenience store. This hierarchy is also visible in the ways men enact their masculinity, physicality, and dominance:

Definitely there is a hierarchy. A higher-status sex worker will get money off the lower ones. . . Not all the time, but they wouldn't think twice about taking money off the others. There is violence from customers to the lads but also among the lads themselves. Even though they would say they are friends, the threat of violence is a constant. There is an age thing, with some of the older ones bullying the younger ones a bit, but there is also a physicality thing too. . . Who comes off best will depend on who is the fittest. (Men's Room interview)

At the bottom are those MSWs who are perceived as having a serious drug addiction. Such men were largely ostracized: 
The lads don't like people who use crack on the beat and they don't like heroin users. A lot of the lads we work with, if somebody like that came onto their part of the canal, they'd say "hey you crackhead, sling it, clear off". ... So there is a big difference between those that use Class A [hard drugs] and those that don't. (Lifeshare interview)

Many MSWs self-police what they perceive to be their territory in ways that clearly demarcate in-group and out-group boundaries. In the case mentioned above, hard drug users are relegated to an out-group status. In general though, this hierarchy coexists with a strong sense of camaraderie and belonging among MSWs who work the streets of Manchester (Men's Room interview).

\section{Conclusion}

Comparative analyses of male and female prostitution, at the same echelon in the same city, are rare, yet a comparative approach is arguably best suited to distinguishing what is generic from what is gendered in commercial sex work. The current study utilized this research design by examining a single type (street-level commerce) in a city with distinct male and female street markets. Although the paper focuses on Manchester's male sector, we also identified key similarities and differences between it and the female street market. Our findings point to the following differences between the two sectors:

- Age Profile: The MSWs skew substantially younger than their female counterparts. This also means that underage prostitution is more prevalent within Manchester's male street sector.

- Sexual Orientation: Among Manchester's male sex workers, those who identify as heterosexual vs. gay/bi tend to have different trajectories and options. Variation in sexual orientation has been documented in other studies of male prostitution, but significantly less attention has been devoted to the ways in which one's sexuality may 
condition working options and experiences, something that we documented here. Sexual orientation also influenced whether the MSW would engage in crime and thus come into contact with the criminal justice system. Sexual orientation is a less robust variable among the female street workers.

- Migrants: Unlike the female sector, the male sector has not experienced the entry of migrants from outside the UK. The influx of Romanians into the female street scene has resulted in a cleavage between the domestic and foreign women. As in other parts of Western Europe, Romanians working in Manchester have acquired a reputation for aggressive solicitation methods, for engaging in risky sexual practices, and for undercutting the prices charged by local sellers (Marttila 2008; Tani 2002; Weitzer and Boels 2015).

The two markets differ ecologically as well. Differences between the male and female strolls - in their physical and social landscapes - have important implications for the actors involved. Like other single-use red-light zones, Manchester's female street prostitution sector has few amenities and "no spatial links with a wider entertainment industry" (Ashworth et al. 1988, 208). Because they operate in a multi-use area in and near the gay Village, male sellers have a much wider range of activities and opportunities available to them. They benefit "by the location of prostitution close to other entertainment facilities" (Ashworth et al.1988, 208) and are therefore more integrated into the surrounding social and economic order than their female counterparts. They are also less identifiable (as sex workers) and thus less likely to attract the attention of the police. The different social ecologies are related to other outcomes as well:

- Victimization: There are greater risks of victimization in the female zone, due to their isolation from, say, merchants who might intervene in the event of an altercation on the street. Female sellers were often subjected to harassment and other nuisances from 
individuals driving by in cars, and were also considerably more at risk of violence from clients. Risk of victimization for males was more likely to come from other young men, not clients.

- Mobility: To a far greater extent than female sellers, we observed that males exercised more spatial mobility when soliciting for clients. This involved considerable time walking either individually or in small groups. Cross-sectoral mobility was also more noticeable within the male sector, with some alternating between the streets, bars, and the Internet depending on circumstances. Cross-sectoral mobility was not evident among female sellers, largely because their typically chaotic lifestyles and drug dependency make it difficult to work in more structured, indoor locations.

- Options: As a result of working in a remote area with few amenities and businesses nearby, the women are limited in their cultural tool kits (Swidler 1986) and repertoires for enterprising activity (Staats 1995). By contrast, because of greater opportunities in the settings where the MSWs work and their closer integration into the pulse of city life, they are able to employ a number of repertoires to earn money - including scams and crimes such as shoplifting and recreational drug dealing. For some MSWs, selling sex is something they engage in instrumentally as the need arises, whereas the women are more dependent on prostitution for their livelihood (cf. Weinberg et al. 1999). At the same time, working within the Village provides marginal young men with an identity and sense of purpose that they may not be able to find otherwise. By contrast, their female counterparts may be involved in street work largely for economic reasons. In other words, the two groups' use of space differs significantly.

Empirically grounded studies like the current one can capture important variations and nuances in street prostitution. Such differences have important implications not just for outreach workers but also for local government policies. Service-provision and exit strategies 
geared to MSWs in Manchester should be more cognisant of the multifaceted dynamics of male sexual commerce in this city, where sellers draw from different repertoires as the need and opportunity arises. The male sector raises some issues that are distinct from the female sector and that deserve attention in their own right.

Acknowledgements. We are grateful to Mary Laing and the anonymous reviewers for their helpful comments on an earlier version of this article. We are also indebted to our interviewees at The Men's Room, Lifeshare, MASH, National Ugly Mugs, the Greater Manchester Police Community Safety Unit, and the Manchester City Council.

Declaration of Conflicting Interests. The authors declared no potential conflicts of interest with respect to the research, authorship, or publication of this article.

Funding. The authors received financial support for this study from the Leverhulme Trust / British Academy, grant number SG122449.

\section{Endnotes}

${ }^{1}$ Both authors were researchers on a larger project that examined the regulation of prostitution in Manchester and three other European cities (Belfast, Berlin, Prague). The first author collected the Manchester data. For ease of presentation, the term "we" is used in the paper, bearing in mind this caveat.

2 Interviews with NGOs asked respondents about sex workers' demographic profile, their use of space, substance abuse, involvement in crime, and risk-reduction strategies. NGOs were also asked to describe what they felt to be the key issues affecting particular groups of sellers. This helped to highlight differences between the two sectors and within each sector. 


\section{REFERENCES}

Aggleton, P., ed. 1999. Men Who Sell Sex. Philadelphia: Temple University Press.

Atkins, M. 2013. Cruising the Village: A Visual Ethnography of Public Sex between Men in Manchester City Center. PhD thesis, University of Manchester.

Atkins, M. 2015. "Mates From the Pub: The Unsettling of Sex Work through Stories of Exchange among Men 'Doing Business' in Manchester.” In Queer Sex Work, edited by M. Laing, K. Pilcher, and N. Smith, 200-15. London: Routledge.

Atkins, M. and M. Laing. 2012. "Walking the Beat and Doing Business: Exploring Spaces of Male Sex Work and Public Sex." Sexualities 15: 622-42.

Ashworth, G., P. White, and H. Winchester. 1988. "The Red-Light District in the West European City." Geoforum 19: 201-12.

Balfour, R. and J. Allen. 2014. A Review of the Literature on Sex Workers and Social Exclusion. Institute of Health Equity, Department of Health, University College London.

Binnie, J. and B. Skeggs. 2004. "Cosmopolitan Knowledge and the Production and Consumption of Sexualized Space: Manchester’s Gay Village.” Sociological Review 52: 39-61.

Brewis, J. and G. Jack. 2010. "Consuming Chavs: The Ambiguous Politics of Gay Chavism.” Sociology 44: 251-68.

Calhoun, T. and G. Weaver. 1996. "Rational Decision-Making among Male Street Prostitutes." Deviant Behavior 17: 209-27.

Davies, P. and R. Feldman. 1999. "Selling Sex in Cardiff and London." In Men Who Sell Sex, edited by P. Aggleton, 1-22. Philadelphia, PA: Temple University Press. 
Dennis, J. 2008. "Women are Victims, Men make Choices: The Invisibility of Men and Boys in the Global Sex Trade." Gender Issues 25: 11-25.

El-Bassel, N. 2000. "Sex Trading and Psychological Distress in a Street-based Sample of LowIncome Urban Men.” Journal of Psychoactive Drugs 32: 259-67.

Hester, M., and N. Westmarland. 2004. Tackling Street Prostitution: Toward a Holistic Approach. London: Home Office.

Institute of Alcohol Studies. 2013. Young People and Alcohol Factsheet, London: Institute of Alcohol Studies. Available at: www.ias.org.uk

Johnson, P. 2008. “ 'Rude Boys': The Homosexual Eroticization of Class.” Sociology 42: 65-82.

Koken, J., D. Bimbi, and J. Parsons. 2010. "Male and Female Escorts: A Comparative Analysis." In Sex For Sale, edited by R. Weitzer, 205-32. London: Routledge.

Lankenau, S. 2005. "Street Careers: Homelessness, Drug Use, and Sex Work among Young Men who Have Sex with Men.” International Journal of Drug Policy 16: 10-18.

Leary, D. and V. Minichiello. 2007. "Exploring the Interpersonal Relationships in Street-based Male Sex Work.” Journal of Homosexuality 53: 75-110.

Linz, D. 2004. "An Examination of the Assumption that Adult Businesses are Associated with Crime in Surrounding Areas." Law and Society Review 38: 69-104.

Mai, N. 2011. "Tampering with the Sex of 'Angels': Migrant Male Minors and Young Adults Selling Sex in the EU.” Journal of Ethnic Migration Studies 37: 1237-52.

Manchester City Council. 2014. Manchester Prostitution Strategy, 2013/2014. 
Marttila, A. 2008. "Desiring the 'Other': Prostitution Clients on a Transnational Red-Light District in the Border Area of Finland, Estonia, and Russia." Gender, Technology, and Development 12: $31-51$.

McCabe, I. 2011. "Male Street Prostitution in Dublin.” Journal of Homosexuality 58: 998-1021.

McKeganey, N., M. Barnard, and M. Bloor. 1990. "A Comparison of HIV-related Risk Behavior and Risk Reduction between Female Street Working Prostitutes and Male Rent Boys in Glasgow." Sociology of Health and Illness 12: 274-92.

Minichiello, V. 2001. "Male Sex Workers in Three Australian Cities.” Journal of Homosexuality 42: 29-51.

Minichiello, V., J. Scott, and D. Callander. 2013. "New Pleasures and Old Dangers: Reinventing Male Sex Work.” Journal of Sex Research 50: 263-75.

Morse, E., P. Simon, and K. Burchfiel. 1999. "Social Environment and Male Sex Work in the United States.” In Men Who Sell Sex, edited by P. Aggleton, 83-101. Philadelphia, PA: Temple University Press.

National Advisory Committee on Drugs. 2009. Drug Use, Sex Work, and the Risk Environment in Dublin. Dublin: Stationary Office.

Pitcher, J., R. Campbell, P. Hubbard, M. O’Neill, and J. Scoular. 2006. Living and Working in Areas of Street Sex Work. Bristol, UK: Policy Press.

Porter, J. and L. Bonilla. 2010. "The Ecology of Street Prostitution.” In Sex For Sale, edited by R. Weitzer, 163-85. London: Routledge.

Prior, J., and P. Crofts. 2012. "Effects of Sex Premises on Neighborhoods." New Zealand Geographer 68: 130-40. 
Reckless, W. 1926. "The Distribution of Commercialized Vice in the City: A Sociological Analysis." Publications of the American Sociological Society 20: 164-76.

Reckless, W. 1933. Vice in Chicago. Chicago, IL: University of Chicago Press.

Scott, M. 2001. Street Prostitution. Washington, DC: U.S. Department of Justice.

Shaw, C. and H. McKay. 1942. Juvenile Delinquency and Urban Areas. Chicago, IL: University of Chicago Press.

Slater, C. 2013. "Rape Fiend Attacked Four Women in Manchester in Less Than an Hour." Manchester Evening News, September 7.

Staats, A. 1995. Behavior and Personality. New York: Springer.

Swidler, A. 1986. “Culture in Action.” American Sociological Review 51: 273-86.

Tani, S. 2002. "Whose Place is this Space? Life in the Street Prostitution area of Helsinki, Finland." International Journal of Urban and Regional Research 26: 343-59.

van der Poel, S. 1992. "Professional Male Prostitution." Crime, Law, and Social Change 18: 25975.

Ward, H. and S. Day. 2006. “What Happens to Women Who Sell Sex?” Journal of Transmitted Infections 82: 413-17.

Weinberg, M, F. Shaver, and C. Williams. 1999. "Gendered Prostitution in the San Francisco Tenderloin." Archives of Sexual Behavior 28: 503-21.

Weitzer, R. 2009. “Sociology of Sex Work,” Annual Review of Sociology 35: 213-34. 
Weitzer, R. 2012. Legalizing Prostitution: From Illicit Vice to Lawful Business. New York: New York University Press.

Weitzer, R. 2014. “The Social Ecology of Red-Light Districts: A Comparison of Antwerp and Brussels." Urban Affairs Review 50: 702-30.

Weitzer, R. and D. Boels. 2015. “Ghent's Red-Light District in Comparative Perspective.” Sexuality Research and Social Policy 12: 248-60.

West, C. and D. Zimmerman. 1987. “Doing Gender.” Gender and Society 1: 125-51.

West, D. 1993. Male Prostitution. Binghamton, NY: Hayworth.

Whowell, M. 2010. "Male Sex Work: Exploring Regulation in England and Wales.” Journal of Law and Society 37: 125-44.

Young, J. 1999. The Exclusive Society: Social Exclusion, Difference, and Crime in Late Modernity. London: Sage.

\section{Author Biographies}

Graham Ellison is a Reader in Criminology at Queens University in Belfast. His primary research area is policing, which includes the regulation of sexual commerce. His books include The Crowned Harp: Policing Northern Ireland (with Jim Smyth), Globalization, Police Reform and Development: Doing it the Western Way? (with Nathan Pino), and Policing in an Age of Austerity: A Postcolonial Perspective (with Mike Brogden).

Ronald Weitzer is Professor of Sociology at George Washington University. He has published extensively in the sex work area and is the editor of Sex For Sale (Routledge, 2010) and Legalizing Prostitution (NYU Press, 2012). He co-edited a special issue of The Annals, on human trafficking, published in May 2014. 


\section{Figures}

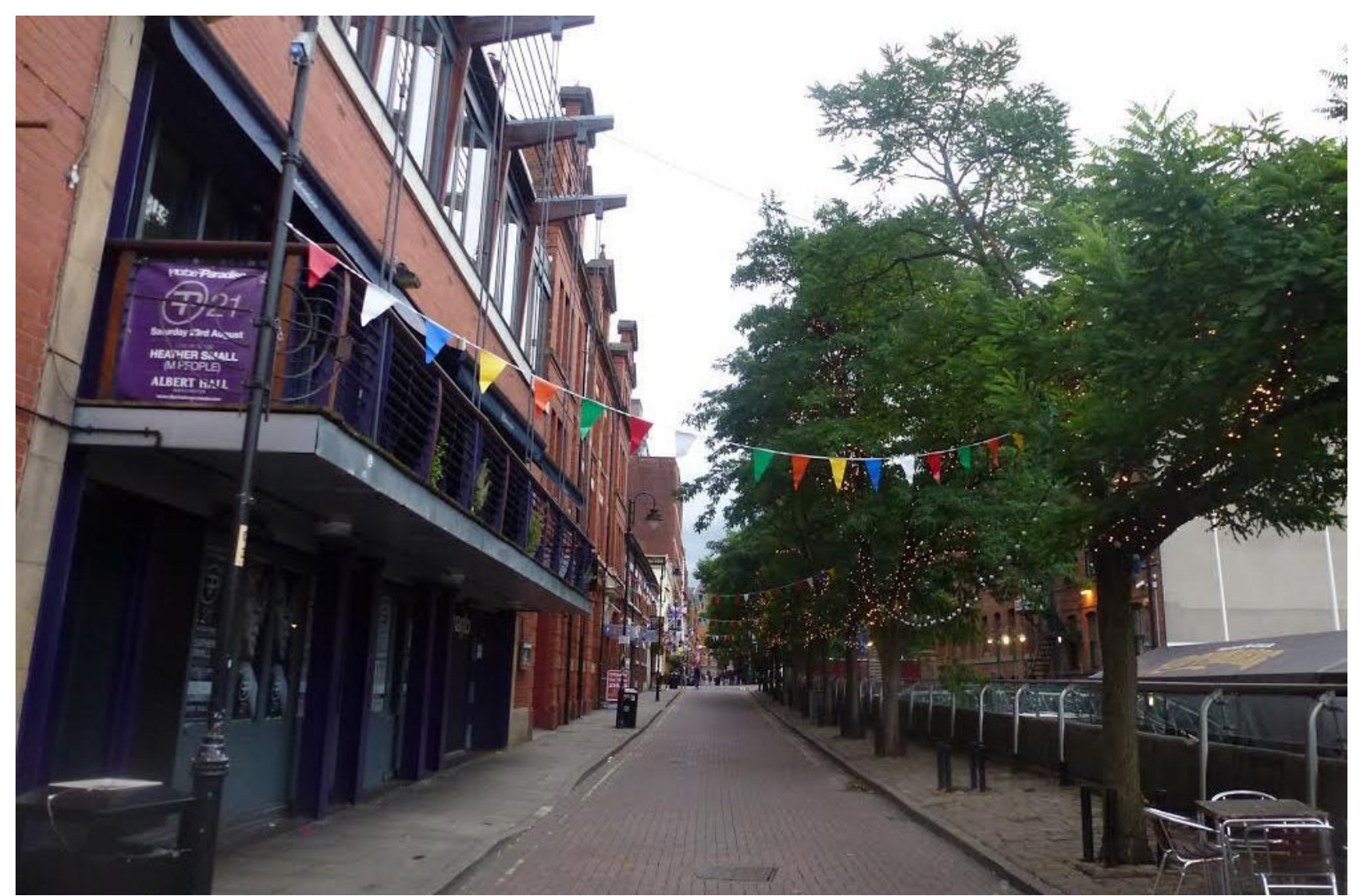

Figure Error! Main Document Only:: The Village

(c) Mikey@Flickr, Creative Commons

https://www.flickr.com/photos/raver_mikey/14986759360 


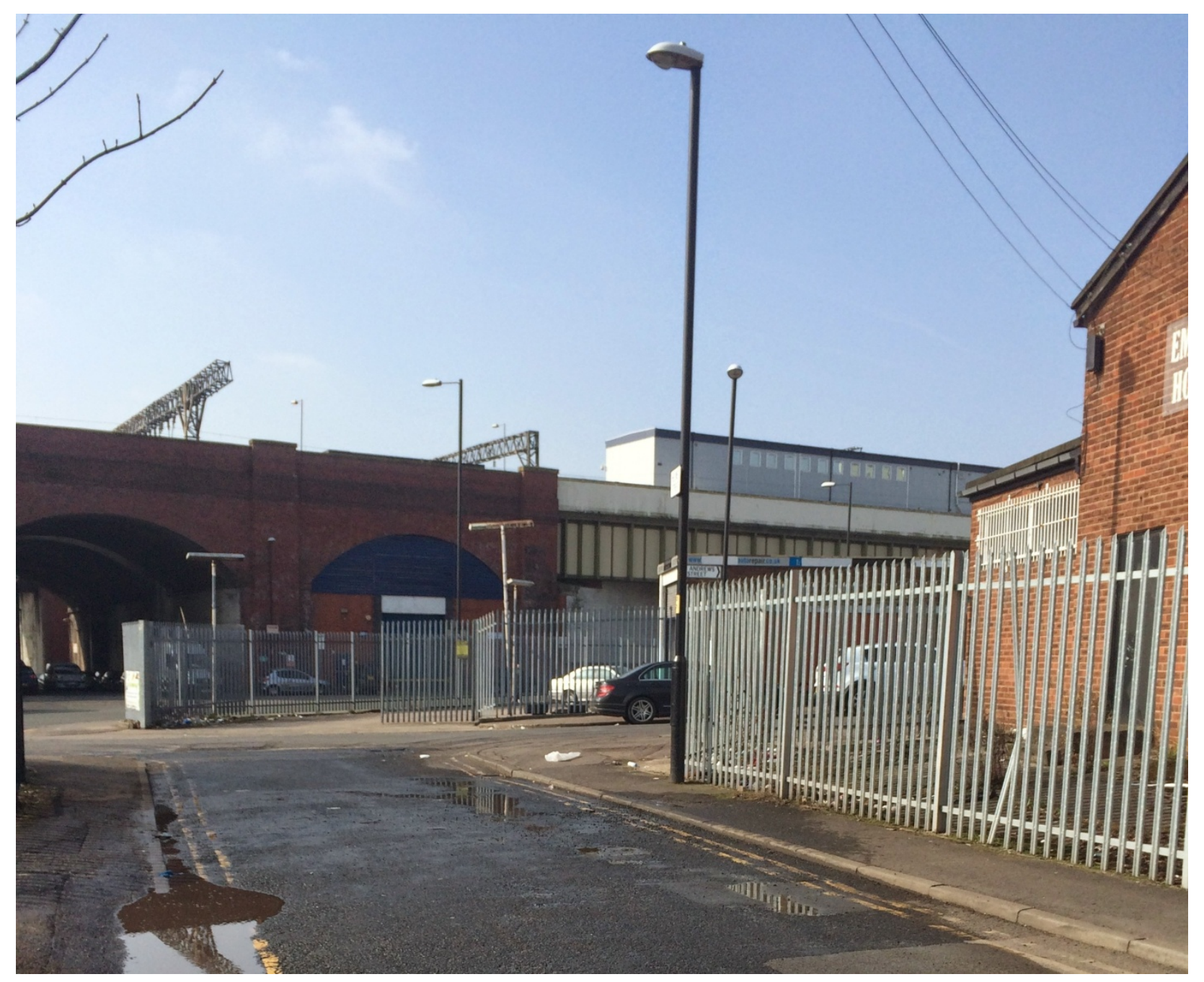

Figure 2: The Women's Zone 


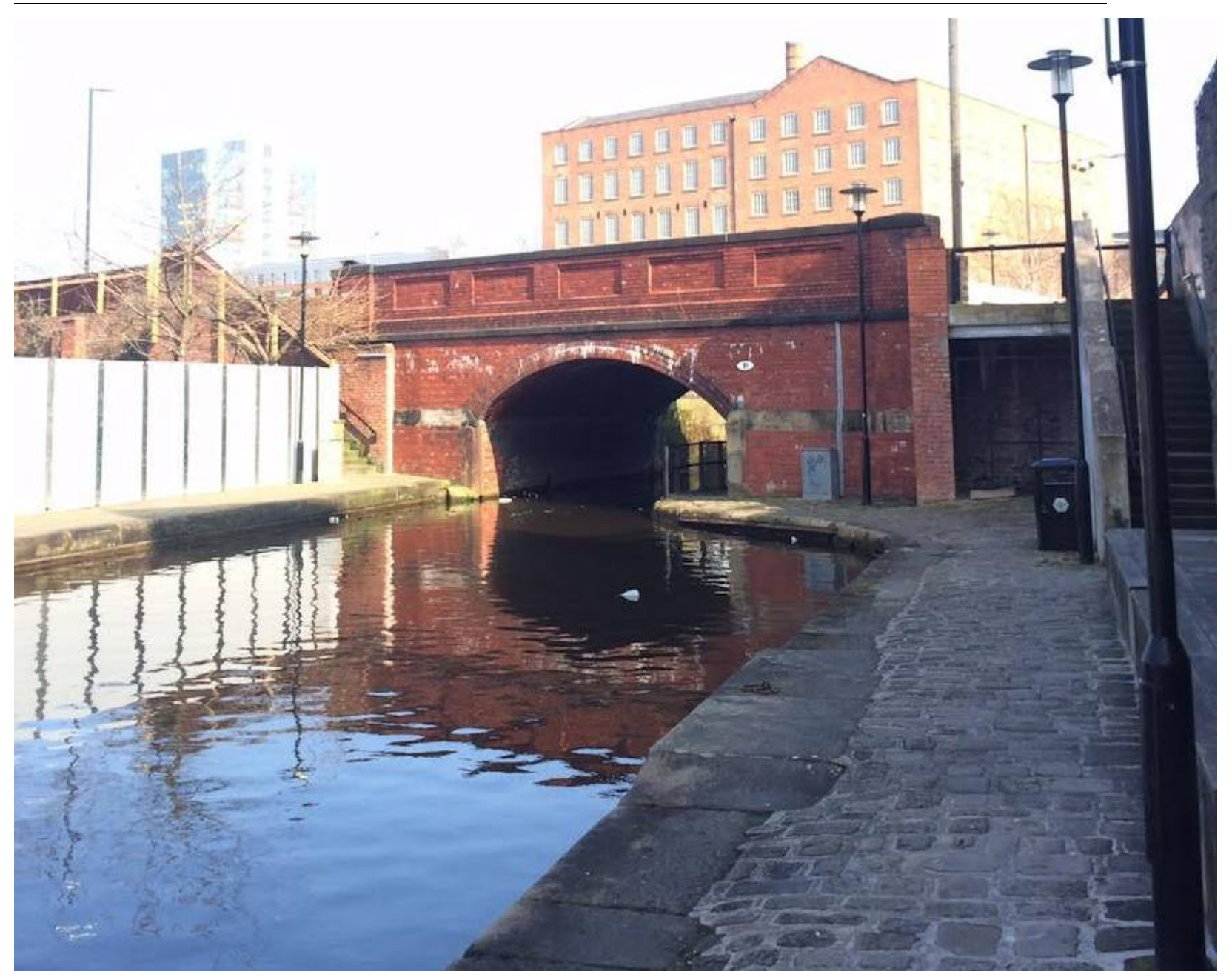

Figure 3: The Bridge 